\title{
How should Helicobacter pylori infected children be managed?
}

\author{
M Rowland, C Imrie, B Bourke, B Drumm
}

It is now recognised that Helicobacter pylori, like most enteric infections, is mainly acquired in childhood. ${ }^{1}$ Adults rarely become infected, with seroconversion rates varying between 0.33 and $0.5 \%$ per person year. ${ }^{2}{ }^{3}$ The age at which children are most likely to become infected is still unclear, but findings in a number of crosssectional studies suggest that infection is acquired before the age of five. ${ }^{4-6}$ The prevalence of infection is highest in children in the developing world where up to $75 \%$ of children may be infected by the age of $10 .^{7}$ In the developed world the prevalence of infection is noticeably increased among socially deprived children. $^{89}$

The diagnosis of $H$ pylori infection in childhood is most often made at endoscopy, for which there are many indications. Symptoms such as abdominal pain, vomiting, and haematemesis may be associated with duodenal ulcer and $H$ pylori infection. However, in the case of children undergoing endoscopy for assessment of oesophagitis, failure to thrive, coeliac disease, Crohn's disease, or portal hypertension, the finding of $H$ pylori infection is likely to be incidental. How should we manage these children with a diagnosis of $H$ pylori infection?

Currently, there are no consensus guidelines for the management of $H$ pylori infected children. In 1994 the National Institutes of Health consensus statement recommended that adults with gastric or duodenal ulcer disease, who are infected with $H$ pylori, should receive antimicrobial treatment. ${ }^{10}$ The European Maastricht Consensus Report suggested broader indications for treatment of infected adults. ${ }^{11}$ It states that treatment is advisable for all $H$ pylori infected dyspeptic patients diagnosed non-invasively under 45 years of age at a primary care level. Patients older than 45 years with dyspeptic symptoms should be treated for $H$ pylori infection but only after endoscopy to rule out any other underlying pathology. ${ }^{11}$ The European guidelines also recommend treatment for infected patients with mucosa associated lymphoid tissue lymphoma and patients who are found to have intestinal metaplasia and gastric atrophy. ${ }^{11}$

Paediatrics,

University College

Dublin,

Children's Research

Centre,

Our Lady's Hospital

for Sick Children,

Crumlin,

Dublin 12, Ireland

Correspondence to: Dr Rowland.
In children, as in adults, long term healing of duodenal ulcer disease is achieved following eradication of $H$ pylori. ${ }^{12}$ All $H$ pylori infected children with a duodenal ulcer should therefore have treatment to eradicate infection.

\section{Possible indications for treatment of $H$ pylori infected children}

Duodenal ulcer disease associated with $H$ pylori is the only definite indication to treat this infection in children. There is controversy as to other possible indications for the treatment of $H$ pylori infection in children.

PREVENTION OF DUODENAL ULCER DISEASE

Duodenal ulcer disease is a rare condition in children under 10 years of age. ${ }^{13}$ It is estimated that $15 \%$ of individuals infected with $H$ pylori will develop a duodenal ulcer as adults. Whether eradication of $H$ pylori is justified in order to reduce the risk of developing duodenal ulcer disease is unknown at this point. In a recent study individuals infected with $H$ pylori who had a family history of endoscopically verified ulcer had a much greater risk of developing ulcer disease. ${ }^{14}$ Although the study did not control for socioeconomic status, it may be reasonable to treat $H$ pylori gastritis in a child whose father or mother has a definite history of peptic ulcer disease.

RECURRENT ABDOMINAL PAIN

Although most studies have found no association between $H$ pylori infection and abdominal pain in children, ${ }^{15} 16$ a number have suggested that $H$ pylori infection may be the cause of recurrent abdominal pain. ${ }^{17} 18$ However, it is vital that symptoms are only evaluated in a situation where the investigator is unaware of the $H$ pylori status of the child. In a meta-analysis McArthur et al found that recurrent abdominal pain is not associated with an increased prevalence of $H$ pylori associated gastritis. ${ }^{19} \mathrm{H}$ pylor $i$ infected children cannot be differentiated from those who are not infected on the basis of their presenting symptoms. ${ }^{2021}$ $H$ pylori eradication is associated with an improvement in symptoms in children who have duodenal ulcer disease but not in those with gastritis alone. ${ }^{20}$ This suggests that the effect of $H$ pylori eradication on symptoms in these children relates to healing of duodenal ulcer disease rather than clearing of gastritis.

Furthermore $H$ pylori infection frequently occurs in asymptomatic children. ${ }^{489}$ Bode et $a l$, in a large epidemiological study of healthy children, showed that $H$ pylori is not a cause of gastrointestinal symptoms. ${ }^{22}$ In fact two studies suggest that children with symptoms of recurrent abdominal pain are less likely to be infected with $H$ pylori. ${ }^{22}{ }^{23}$ There is therefore no clear evidence that treatment of $H$ pylori will alleviate symptoms in children with recurrent abdominal pain who have $H$ pylori gastritis. 
IRON DEFICIENCY ANAEMIA

There have been a number of case reports describing children with refractory sideropaenic anaemia which only responded to treatment after eradication of $H$ pylori ${ }^{24-26}$ A recent report by Milman et al suggests that serum ferritin concentrations are reduced in $H$ pylori infected adults. ${ }^{27}$ They suggest that $H$ pylori may interfere with iron metabolism in humans. This may be an important issue in children who have lower iron stores than adults and may be at a greater risk of developing anaemia. Further research is required to assess the contribution of socioeconomic status and dietary factors to low iron stores in $H$ pylori infected individuals. However, based on our present knowledge, children with iron deficiency anaemia which is refractory to treatment should be screened for $H$ pylori and treated if infection is present.

SHORT STATURE

Oderda et al have shown that $H$ pylori infection is not associated with short stature. ${ }^{28}$ Previous reports of such an association ${ }^{29}$ failed to control for socioeconomic status as a risk factor for short stature. Short stature is therefore not an indication to treat $H$ pylori.

PERSISTENT DIARRHOEA

In developing countries some investigators have suggested that $H$ pylori may be associated with chronic diarrhoea. ${ }^{30}$ It is speculated that infection with $H$ pylori at a young age may induce hypochlorhydria which interferes with the normal acidic barrier in the stomach. This acidic barrier is important in preventing infection with many gastrointestinal organisms. ${ }^{30}$ Further studies are required in this group of children to determine whether eradication of $H$ pylori reduces the prevalence of chronic diarrhoea.

GASTRIC CANCER

$H$ pylori has been classified as a group I carcinogen by the World Health Organisation. ${ }^{31}$ The relative risk of gastric carcinoma is $2.3-8.7$ times greater in infected adults compared with uninfected controls. ${ }^{32}$ However, only about $1 \%$ of $H$ pylori infected individuals will develop gastric cancer.

$H$ pylor $i$ is possibly only one risk factor in the cascade which leads to gastric cancer. Its importance in this cascade is unknown. If it is considered justified to eradicate $H$ pylori in order to reduce the risk of gastric cancer, treatment in early life is likely to be most effective. Correa's model for the development of gastric cancer proposes a progression from gastritis to gastric atrophy and intestinal metaplasia followed by dysplasia. ${ }^{33}$ Development of gastric atrophy is related to the duration of infection with $H$ pylori $i^{2}$ rather than a direct result of ageing. Treatment of $H$ pylori infection in adult life may therefore be too late to reduce the risk of developing gastric cancer as atrophy may have already developed. If we consider atrophy to be present only when there is evidence of fibrosis and thinning of the lamina propria with replacement of the gastric epithelium with intestinal type epithelium, then it is unlikely that the process is reversible. ${ }^{34}$ Intestinal metaplasia has never been shown to regress.

In order for any intervention strategy to be calculated to be cost effective, the time period between intervention measures and the occurrence of gastric cancer must be relatively short. ${ }^{35} \mathrm{~A}$ decision analysis model has shown that treatment of individuals in the 50-55 age group is potentially cost effective. ${ }^{36}$ However in clinical practice treatment of people over the age of 50 years is unlikely to reverse the progression from $H$ pylori gastritis to gastric cancer in susceptible individuals. Treatment at a much younger age may be effective but this would be prohibitively expensive.

A consensus has yet to be reached on the need to treat infected children because of the increased risk of developing gastric cancer at some time in the future. Furthermore, if we decide to treat these children it implies that we should also be screening all children for this infection.

\section{Treatment of children}

Compliance is a very important factor in achieving high eradication rates in children. ${ }^{37} 38$ Recently, a one week treatment regimen comprising colloidal bismuth subcitrate $480 \mathrm{mg} / 1.73 \mathrm{~m}^{2} /$ day (maximum $120 \mathrm{mg}$ qid), clarithromycin $7.5 \mathrm{mg} / \mathrm{kg} /$ day (maximum $250 \mathrm{bid}$ ), and metronidazole $20 \mathrm{mg} / \mathrm{kg} /$ day (maximum $200 \mathrm{mg}$ tid) eradicated $H$ pylori in 21 of 22 children. ${ }^{38}$ Only two children experienced diarrhoea and vomiting. The short duration of treatment probably improved compliance as did the use of a redidose box with individual compartments for each dose of medication. It is questionable whether this level of compliance could be achieved in routine practice and the effectiveness of a one week regimen needs to be assessed under such circumstances.

Gormally et al reported eradication of the organism in $84 \%$ using metronidazole and bismuth for two weeks. ${ }^{20}$ The strong taste of ammonia associated with liquid bismuth may reduce compliance. Regimens using a proton pump inhibitor instead of bismuth may therefore be more attractive. Two weeks' treatment with metronidazole, omeprazole and clarithromycin was successful in $93 \%(14 / 15)$ of children. ${ }^{39}$ A one week treatment regimen using omeprazole (20 mg bid), clarithromycin (250 $\mathrm{mg}$ bid) and tinidazole or metronidazole (500 mg bid) eradicated $H$ pylori in 24 (89\%) of 27 patients who were treated for the first time. ${ }^{40}$ However, in children in whom treatment for $H$ pylori infection had failed previously this regimen was ineffective.

\section{SIDE EFFECTS}

Although concern has been expressed about the use of bismuth salts in children, none of the potential toxic side effects has been reported in children treated for $H$ pylori infection. Few side effects have been reported associated with the use of clarithromycin. There 
has been a recent report of Clostridium difficile colitis associated with clarithromycin, metronidazole and omeprazole triple therapy in a 54 year old man. ${ }^{41}$

The emergence of metronidazole resistant strains is a concern. Raymond et al detected metronidazole resistance in $26 \%$ (six of 23 ) of children in France using an E-test. ${ }^{42}$ Only one in six children with a metronidazole resistant strain was successfully treated for $H$ pylori infection. This is in contrast to studies in adults which suggest that even if metronidazole resistance is detected, eradication rates with triple metronidazole based therapy are higher than expected. ${ }^{43}$

\section{Reinfection}

$H$ pylori infection is clustered within families and in institutions for the mentally handicapped. However, reinfection in adults ${ }^{44} 45$ and older childre ${ }^{46}$ following successful treatment is rare. Therefore, there is no need to treat the entire family to prevent reinfection.

\section{$H$ pylori testing following treatment}

In adults there is debate on the need to assess whether treatment has been successful or not because of the high success rates achieved. The success of treatment regimens for children in a primary care setting is unknown. If we decide to treat a child for $H$ pylori infection we should assess whether that treatment has been successful. This can now be achieved noninvasively using the ${ }^{13} \mathrm{C}$-urea breath test which is $100 \%$ sensitive and specific for the diagnosis of $H$ pylori following treatment. ${ }^{47}$

\section{Conclusions}

All children with a duodenal ulcer who have $H$ pylori infection should receive treatment for the infection. If infected children have a strong family history of duodenal ulcer disease or gastric cancer, treatment should be considered. Children with sideropaenic anaemia which is refractory to treatment with iron should be screened for $H$ pylori infection and if infected, treatment may be of benefit.

There is no indication to screen children with recurrent abdominal pain for $H$ pylori infection. Eradication of infection in such individuals has, in most studies, resulted in no improvement in the pain. Consensus is required on the need to treat $H$ pylori infected children in relation to the possible risk of developing gastric cancer. We need to decide whether a screening programme for the identification and treatment of $H$ pylori infected children is justified in terms of reducing the prevalence of gastric cancer.

1 Banatvala N, Mayo K, Megraud F, et al. The cohort effect and Helicobacter pylori. F Infect Dis 1993;168:219-21.

2 Kuipers EJ, Uyterlinde AM, Pena AS, et al. Long-term sequelae of Helicobacter pylori gastritis. Lancet 1995;345: 1525-8.

3 Cullen DJ, Collins BJ, Christiansen KJ, et al. When is Helicobacter pylori infection acquired? Gut 1993;34:16812 .

4 O'Donohoe JM, Sullivan PB, Scott R, et al. Recurrent abdominal pain and Helicobacter pylori in a communitybased sample of London children. Acta Pediatr 1996;85: 961-4.
5 Lindkvist P, Asrat D, Nilsson I, et al. Age at acquisition of Helicobacter pylori infection: comparison of a high and low Helicobacter pylori infection: comparison of a high and
prevalence country. Scand 7 Infect Dis 1996;28:181-4.

prevalence country. Scand f Infect Dis 1996;28:181-4.
6 Mitchell HM, Li YY, Hu PJ, et al. Epidemiology of Helicobacter pylori in Southern China: identification of early childhood as the critical period for acquisition. $\mathcal{F}$ Infect Dis 1992;166:149-53.

7 Perez-Perez GI, Taylor DN, Bodhidatta L, et al. Seroprevalence of Helicobacter pylori infections in Thailand. F Infect Dis 1990;161:1237-41.

8 Fiedorek SC, Malaty HM, Evans DL, et al. Factors influencing the epidemiology of Helicobacter pylori infection in children. Pediatrics 1991;88:578-82.

9 McCallion WA, Murray LJ, Bailie AG, et al. Helicobacter pylori infection in children: relation with current household living conditions. Gut 1996;39:18-21.

10 NIH Consensus Development Panel. Helicobacter pylori in peptic ulcer disease. NIH Consensus Statement 1994;12:1-19.

11 The European Helicobacter pylori Study Group. Current European concepts in the managemant of Helicobacter
pylori infection. The Maastricht Consensus Report. Gut 1997;41:8-13.

12 Goggin N, Rowland M, Imrie C, et al. Effect of Helicobacter pylori eradication on the natural history of duodenal ulcer disease. Arch Dis Child 1998;79:502-5.

13 Drumm B, Rhoads JM, Stringer DA, et al. Peptic ulcer disease in children: etiology, clinical findings, and clinical course. Pediatrics 1988;82:410-14

14 Brenner H, Rothenbacher D, Bode G, et al. The individual and joint contributions of Helicobacter pylori infection and family history to the risk for peptic ulcer disease. F Infect Dis 1998;117:1124-7.

15 van der Meer SB, Forget PP, Loffeld RJ, et al. The prevalence of Helicobacter pylori serum antibodies in chil-
dren with recurrent abdominal pain. Eur $\mathcal{f}$ Pediatr 1992;151:799-801.

16 McCallion WA, Bailie AG, Ardill JE, et al. Helicobacter pylori, hypergastrinaemia, and recurrent abdominal pain in pylori, hypergastrinaemia, and recurrent
children. F Pediatr Surg 1995;30:427-9.

17 Chong SK, Lou Q, Asnicar MA, et al. Helicobacter pylori infection in recurrent abdominal pain in childhood: comparison of diagnostic tests and therapy. Pediatrics 1995; 96:211-15.

18 Heldenberg D, Wagner Y, Heldenberg E, et al. The role of Helicobacter pylori in children with recurrent abdominal pain. Am f Gastroenterol 1995;90:906-9.

19 Macarthur C, Saunders N, Feldman W. Helicobacter pylori, gastroduodenal disease, and recurrent abdominal pain in children. $7 A M A$ 1995;273:729-34.

20 Gormally SM, Prakash N, Durnin MT, et al. Association of symptoms with Helicobacter pylori infection in children. $\mathcal{F}$ Pediatr 1995;126:753-6.

21 Reifen R, Rasooly I, Drumm B, et al. Helicobacter pylori infection in children. Is there specific symptomatology? Dig Dis Sci 1994;39:1488-92

22 Bode G, Rothenbacher D, Brenner H, et al. Helicobacter pylori and abdominal symptoms: a population-based study among preschool children in southern Germany. Pediatrics 1998;101:634-7.

23 Hardikar W, Feekery C, Smith A, et al. Helicobacter pylori and recurrent abdominal pain in children. F Pediatr Gastroenterol Nutr 1996;22:148-52.

24 Dufour C, Brisigotti M, Fabretti G, et al. Helicobacter pylori gastric infection and sideropenic refractory anaemia. f Pediatr Gastroenterol Nutr 1993;17:225-7.

25 Marignani M, Angeletti S, Bordi C, et al. Reversal of long standing iron defficiency anaemia after eradiacation of Helicobacter pylori. Scand $\mathcal{f}$ Gastroenterol 1997;32:617-22.

26 Carnicer J, Badia R, Argemi J. Helicobacter pylori gastritis and sideropenic refractory anaemia [letter]. $f$ Pediatr and sideropenic refractory anae

27 Milman N, Rosenstock S, Andersen L, et al. Serum ferritin, hemoglobin, and Helicobacter pylori infection: a seroepidemiologic survey comprising 2794 Danish adults. Gastroenterology 1998;115:268-74.

28 Oderda G, Palli D, Saieva C, et al. Short stature and Helicobacter pylori infection in Italian children: prospective multicentre hospital based case-control study. BMF 1998;317: 514-15

29 Patel P, Mendall MA, Khulusi S, et al. Helicobacter pylori infection in childhood: risk factors and effect on growth. BMF 1994;309:1119-23.

30 Dale A, Thomas JE, Darboe MK, et al. Helicobacter pylori infection,gastric acid secretion, and infant growth. $\mathcal{f}$ Pediatr Gastroenterol Nutr 1998;26:393-7.

31 IARC. Monographs on the evaluation of carcinogenic risks to humans. Schistosomes, liver flukes and Helicobacter pylori. Lyon: IARC, 1994:177-240.

32 Forman D, Webb P, Parsonnet J. H pylori and gastric cancer [letter]. Lancet 1994;343:243-4.

33 Correa P. Human gastric carcinogenesis: a multistep, and multifactorial process. First American Cancer Society award lecture on cancer epidemiology and prevention. Cancer Res 1992;52:6735-40.

34 Genta RM. Helicobacter pylori, inflamation, mucosal damage, and apoptosis - pathogenesis and definition of gastric atrophy. Gastroenterology 1997;113:S51-5.

35 Sonnenberg A, Inadomi JM. Review article: medical decision models of Helicobacter pylori therapy to prevent
gastric cancer. Aliment Pharmacol Ther 1998;12S:111-21.

36 Parsonnet J, Harris RA, Hack HM, et al. Modelling cost-effectiveness of Helicobacter pylori screening to prevent gastric cancer: a mandate for clinical trials. Lancet 1996;348:150-4. 
37 Israel DM, Hassall E. Treatment and long-term follow-up of Helicobacter pylori-associated duodenal ulcer disease in children. 7 Pediatr 1993;123:53-8.

38 Walsh D, Goggin N, Rowland M, et al. One week treatment for Helicobacter pylori infection. Arch Dis Child 1997;76: $352-5$

39 Dohil R, Israel DM, Hassall E. Effective 2-wk therapy for Helicobacter pylori disease in children. Am $\mathcal{F}$ Gastroenterol 1997;92:244-7.

40 Moshkowitz M, Reif S, Brill S, et al. One-week triple therapy with omeprazole, clarithromycin, and nitroimidazole for Helicobacter pylori infection in children and adolescents. Pediatrics 1998;102: 14

41 Archimandritis A, Souyioultzis S, Katsorida M, et al. Clostridium difficile colitis associated with a "triple" regime, containing clarithromycin and metronidazole to eradicate Helicobacter pylori. F Intern Med 1998;243:251-3.
42 Raymond J, Kalach N, Bergeret M, et al. Effect of metronidazole resistance on bacterial eradication of Helicobacter pylori in children. Antimicrob Agents Chemother 1998;42: $1334-5$

43 Solnick JV. Antibiotic resistance in Helicobacter pylori. Clin Infect Dis 1998;27:90-2.

44 Borody T, Andrews P, Mancuso N, et al. Helicobacter pylori reinfection 4 years post-eradication. Lancet 1992;339:1295.

45 Forbes GM, Glaser ME, Cullen DJ, et al. Duodenal ulcer treated with Helicobacter pylori eradication: seven-year follow-up. Lancet 1994;343:258-60.

46 Rowland M, Kumar D, O'Connor P, et al. Reinfection with Helicobacter pylori in children. Gastroenterology (in press).

47 Rowland M, Lambert I, Gormally S, et al. Carbon 13-labeled urea breath test for the diagnosis of Helicobacter pylori in children. $\mathcal{F}$ Pediatr 1997;131:815-20. 